\title{
Preparation of MgO-templated carbons from waste polymeric fibres
}

\author{
Beatriz Acevedo, Carmen Barriocanal \\ Instituto Nacional del Carbón, INCAR-CSIC, Apartado 73, 33080 Oviedo, Spain \\ Phone number: +34 9851189 58, email: carmenbr@incar.csic.es
}

\begin{abstract}
Mesoporous carbons with a high surface area were produced using reinforcing fibres from scrap tyres, polyester Dacron ${ }^{\circledR}$, polyamide Nylon6 and a bituminous waste as carbon precursor by two different procedures: physical activation and $\mathrm{MgO}$-templated synthesis. Moreover, MgO-templated synthesis was carried out by means of two different mixing methods: powder- and solution-mixing procedures. The maximum surface area, highest pore volume and mesopore ratio were obtained for $\mathrm{MgO}$ templated carbons. Nanocarbons with narrow pore size distributions showing maxima at $4.5-5 \mathrm{~nm}$ in the case of powder-mixed $\mathrm{MgO}$ templated carbons and at $7 \mathrm{~nm}$ for solution-mixed $\mathrm{MgO}$ templated carbons were obtained. The mesopore size of the carbon-coated materials was in agreement with their crystallite size as determined by X-ray diffraction (XRD). The surface chemistry of the materials was also studied by thermal programmed desorption (TPD), infrared spectroscopy and by determining the $\mathrm{pH}_{\mathrm{pzc}}$. The MgO-templated carbons had acid surface groups, whereas activated carbons had basic surface groups. The adsorption of a reactive dye by two nanocarbons prepared by two different mixing procedures was tested.

Keywords: Reinforcing fibres, tyre waste, mesoporous carbon, templated carbons, activated carbon, adsorption.
\end{abstract}




\section{Introduction}

More than 300 million tons of tyres are discarded every year worldwide. All the materials used in tyre-compounding are totally recyclable. Tyre recycling plants produce a fluff consisting of a mixture of polymeric fibers and rubber particulates that cannot be further separated and are disposed of at landfill sites. This fluff comes from the textile fibres used as reinforcement in tyres [1]. Pyrolysis is a process that allows the decomposition of waste tyres into gas, pyrolytic oil and char, all of which are highly useful products. The oil and gas can be used to generate the energy needed to operate the recycling plant itself while the char can provide mesoporous carbons with a high surface area for use as adsorbents of pollutants [2].

Mesoporous carbon has attracted a great deal of attention since it can be applied to many fields such as the adsorption of large molecules, as catalyst supports, carbon electrodes for double-layer supercapacitors, desulfurization for clean energy, etc $[3,4]$.

Activated carbons can be prepared from various carbon precursors by means of pyrolysis followed by physical activation. During activation, micropores are created usually accompanied by meso and macropores that facilitate the diffusion of adsorbates into the microporosity. During recent years various attempts have been made to prepare microporous and mesoporous carbons by means of the template method with zeolite and silica as template [5], since with these materials it is possible to obtain a homogeneous pore size and an optimum morphology. The use of organic templates avoids the need to employ corrosive acids and also yields highly ordered mesopores of a homogenous size [5].

A method that has been studied in the present research work is the preparation of mesoporous carbon materials using $\mathrm{MgO}$ as template. This is a method of template synthesis which is useful for preparing porous carbons with a controlled structure, particularly mesoporous carbons, from thermoplastic carbon precursors without the need for any stabilization or activation processes. In this case, an $\mathrm{MgO}$ precursor is essential, examples of which are magnesium citrate, magnesium acetate, magnesium gluconate, magnesium hydroxyl-carbonate or $\mathrm{MgO}$ itself $[5,6,7]$.

The present study deals with the preparation of mesoporous carbons with a high surface area by means of three different methods: two of which use $\mathrm{MgO}$ as template while the third involves carbonization followed by physical activation. The aim of the present work was to compare the texture and surface chemistry of mesoporous activated carbons with a burn-off of $63 \%$ with MgO-templated carbons in order to find an efficient way to produce mesoporous carbons with a high surface area. The MgO- 
templated carbons were produced using reinforcing fibres derived from scrap tyres and blending them with a bituminous waste in a proportion of $1: 1$

\section{Experimental}

\subsection{Raw materials}

Reinforcing fibres (RF) obtained as a waste during the grinding and shredding of scrap tyres together with a bituminous waste (BWM) obtained from the benzol distillation column of the by-product section of a coking plant were employed as carbon precursor [8]. RF was obtained from the processing of car and truck tyres [1] and is mainly composed of polyester and polyamide $[9,10]$. The main characteristics of these materials are presented in Table S1. For comparison purposes a blend of polyester Dacron ${ }^{\circledR}(\mathrm{Da})$ and polyamide Nylon6 (Ny6) of commercial grade were also used for the preparation of the $\mathrm{MgO}$ templated carbons. Nonahydrated magnesium citrate obtained from Sigma-Aldrich was dried to obtain $\mathrm{Mg}_{3}\left(\mathrm{C}_{6} \mathrm{H}_{5} \mathrm{O}_{7}\right)$ which was used as the $\mathrm{MgO}$ precursor. Cibacron brilliant yellow 3G-P was also obtained from Sigma-Aldrich. Waste materials such as RF and BWM were used as carbon precursor in order to enhance their added value.

\subsection{Preparation of activated carbons}

The activated carbons (ACs) were obtained by means of pyrolysis up to $850{ }^{\circ} \mathrm{C}$ at $5 \mathrm{C} / \mathrm{min}$ under a $\mathrm{N}_{2}$ flow rate of $400 \mathrm{ml} / \mathrm{min}$ in a rotary oven [1]. Activation was carried out in the same oven at $850^{\circ} \mathrm{C}$ with a $\mathrm{CO}_{2}$ flow of $250 \mathrm{ml} / \mathrm{min}$ up to a burn-off of $63 \%$. Two Acs were prepared, one from RF (AC RF) and the other from a 1:1 blend of RF and BWM (AC RF BWM).

\subsection{Preparation of $\mathrm{MgO}$-Templated carbons}

The carbonization tests were carried out in the same oven as that used for the preparation of the ACs. The samples were heated at a rate of $5^{\circ} \mathrm{C} / \mathrm{min}$ to $950^{\circ} \mathrm{C}$ in a nitrogen atmosphere. This temperature was maintained for one hour. The following materials were prepared: C3B (from Mg citrate), C3B Da Ny6 (50:25:25 wt. \%); C3B RF (50:50 wt. \%), C3B RF BWM 50 (50:25:25 wt. \%), C3B RF BWM 40 (40:20:40 wt. $\%)$. The mixing ratio was determined on the basis of the mass of $\mathrm{MgO}$ expected to be formed from the $\mathrm{Mg}$ citrate. The mixture was prepared using two different processes, powder mixing (PM) and solution mixing (SM). In the PM procedure the mixture was heated in air up to the melting temperature of the fibres. Afterwards the mixture was pulverized in an agate mortar and carbonized in a rotary oven. For the blends with BWM the mixtures were prepared in two parts. After the blend of the RF and $\mathrm{MgO}$ precursor had been prepared, BWM was added. The mixture was heated again up to 
the softening temperature of the BWM. The blend was then ground in the agate mortar and carbonized. For the solution mixing procedure (SM), the precursor was imbibed in a solution of $\mathrm{Mg}$ citrate and left to dry. Due to the insolubility of BWM in water, this material was added once the imbibed fibre was dry. After carbonization the $\mathrm{MgO}$ was dissolved using $15 \mathrm{M} \mathrm{HCl}$ for $25 \mathrm{~h}$. The materials obtained were thoroughly washed with distilled water and dried.

\subsection{Characterization}

The elemental analysis was carried out by using a LECO CHN-2000 instrument for C, H and N (ASTM D-5773), a LECO S-144 DR (ASTM D-5016) for sulphur and a LECO VTF-900 for the direct determination of oxygen. The ash content was determined by thermogravimetric analysis using a TA Instruments SDT 2960 thermoanalyser.

The TG/DTG analysis of the Mg citrate, the 1:1 blend of the two polymers ( $\mathrm{Da}$ and Ny6) and their blends ( $\mathrm{Mg}$ citrate, Da and Ny6) prepared by powder and solution mixing, was carried out using a TA Instruments Q600 thermoanalyser. Samples of 15$20 \mathrm{mg}$ were heated using the same program as in the rotary oven under a nitrogen flow of $100 \mathrm{ml} / \mathrm{min}$. From the data obtained by thermogravimetric analysis the derivative of the weight loss curve (DTG curve) was calculated. The temperature corresponding to the maximum volatile matter evolution (Tmax) was derived from the DTG curves.

X-ray diffraction patterns (XRD) of the samples were recorded on a Bruker, D8 Advance instrument using a step size of $0.02^{\circ} \mathrm{s}^{-1}$ and a step time of $2 \mathrm{~s}$. The interlayer spacing, $d_{200}$, was evaluated from the position of the (2 00$)$ peak by applying the Bragg equation. The crystallite size, $D$ was calculated from the $(200)$ peak, using the Scherrer formula, with a $K$ value of 0.9 [11].

The textural properties of the chars were studied by means of $\mathrm{N}_{2}$ adsorption at $77 \mathrm{~K}$ on a Micromeritics ASAP 2420 apparatus. The software package provided with the equipment was used to determine the textural parameters. The specific surface area $\left(\mathrm{S}_{\mathrm{BET}}\right)$ was calculated by means of the BET equation. The total pore volume $\left(\mathrm{V}_{\mathrm{T}}\right)$ was measured at $P / P_{0}=0.97$. The micropore volume $\left(V_{D R, N 2}\right)$ was determined by applying the Dubinin equation to the lower relative pressure zone of the $N_{2}$ isotherm. The mesoporosity was calculated as the difference between the total pore volume and the micropore volume. The pore size distribution was derived from the adsorption branches of the isotherms using the Barrett - Joyner- Halanda (BJH) model. The Harkins and Jura model was employed for the thickness curve and the Faas model for the BJH correction. 
The point of zero charge $\left(\mathrm{pH}_{\mathrm{PzC}}\right)$ was determined according to the procedure described by Moreno-Castilla et al. [12].

Temperature programmed desorption (TPD) analyses were carried out in an Autochem II apparatus (Micromeritics). The samples were heated at a constant heating rate of $10^{\circ} \mathrm{C} / \mathrm{min}$ up to $1000^{\circ} \mathrm{C}$ under an Ar flow of $50 \mathrm{~cm}^{3} / \mathrm{min}$. The desorbed gases were monitored using an Omnistar (Pfeiffer Vacuum) mass spectrometer. The $\mathrm{CO}$ and $\mathrm{CO}_{2}$ desorbed gases were calibrated using a $50 \mathrm{~cm}^{3} / \mathrm{min}$ flow of $1 \% \mathrm{CO}+1 \% \mathrm{CO}_{2}$ in Ar.

The topography of the fractured surfaces of the chars was studied on a Zeiss DSM 942 scanning electron microscope.

The two materials with the highest surface area prepared by different template methods were chosen for the adsorption tests. The adsorption experiments were carried out by shaking $50 \mathrm{mg}$ of C3B RF BWM 50 _PM and_SM adsorbent mixed with $100 \mathrm{~cm}^{3}$ of Cibacron brilliant yellow 3G-P dye (CBY) solution in a concentration of $350 \mathrm{mg} / \mathrm{dm}^{3}$ at $25^{\circ} \mathrm{C}$ in an orbital shaker. The concentration of the dye was measured using a UV-2450, Shimadzu UV-Vis spectrophotometer at a wavelength $404 \mathrm{~nm}$. A digital $\mathrm{pH}$ meter (Crison basic $20 \mathrm{pH}$ ) with a glass electrode was employed to measure the $\mathrm{pH}$ before and after contact.

\section{Results and discussion}

\subsection{Composition of the carbons prepared}

Figure 1 shows the TG and DTG curves corresponding to the Mg citrate, the blend (1:1) of the two polymers and the mixtures prepared by powder mixing and solution mixing of the $\mathrm{Mg}$ citrate and the blend of the two polymers. The blend of these two polymers was chosen because they are both present in RF and melt on heating. $\mathrm{RF}$ is a heterogeneous material and the preparation of small amounts of blends with Mg citrate will involve a high degree of experimental error. A study of the devolatilization of the polymer blend in relation to $\mathrm{Mg}$ citrate such as the one undertaken in this work will be useful for understanding the possible interactions between the the $\mathrm{Mg}$ citrate and the RF. The decomposition of the Mg citrate takes place in two stages, the first at $\operatorname{Tmax}=322^{\circ} \mathrm{C}$ corre sponding to the formation of aconitic acid, which acts as an intermediate in the decomposition of $\mathrm{Mg}$ citrate to $\mathrm{Mg}$ carbonate that will decompose at a higher temperature $\left(\operatorname{Tmax}=496^{\circ} \mathrm{C}\right)$ to form $\mathrm{MgO}$ [13]. The decomposition of the $\mathrm{Mg}$ citrate involves the formation of $\mathrm{MgO}$ and a carbonaceous residue. The decomposition of the polymer blend occurs in one single stage with $\operatorname{Tmax}=380^{\circ} \mathrm{C}$. The pyrolysis of the $\mathrm{Mg}$ citrate will o ccur after the pyrolysis of the carbon precursor has started. Consequently the $\mathrm{Mg}$ citrate will be covered by the 
carbonaceous residue of the pyrolyzed blend of polymers before it starts to decompose itself $[3,5]$. The profile of the TG curve corresponding to the Mg citrate with the polymer blend prepared by powder mixing presents three decomposition stages, the first and third stages corresponding to the decomposition of $\mathrm{Mg}$ citrate to give $\mathrm{MgO}$ and carbon and the second one corresponding to the decomposition of the polymer blend. The final carbon yield obtained is very similar in both cases, around $39 \mathrm{wt} \% \mathrm{db}$. The mixture prepared by solution mixing presents higher temperatures of decomposition and the carbon yield is lower. The carbon obtained from the pyrolysis of the polymer blend and the $\mathrm{Mg}$ citrate covers the $\mathrm{MgO}$ particles formed from the decomposition of the $\mathrm{Mg}$ citrate which makes it possible to retain nano-size MgO particles [5].

The results of the elemental analysis of the ACs and MgO-templated carbons are presented in Table 1. The data are expressed on an ash free basis (daf) to facilitate comparison between the carbons prepared. The MgO templated carbons present ash contents of up to 5 because some of the mineral matter present in RF was not eliminated by the acid treatment. The ACs have higher ash content because they were not subjected to $\mathrm{HCl}$ treatment. The carbon content is similar for all the materials with values in the 93 and $96 \mathrm{wt} \%$ range, whereas the $\mathrm{S}$ content is lower and the $\mathrm{N}$ and $\mathrm{H}$ contents are higher in the $\mathrm{MgO}$ templated carbons. Some of the $\mathrm{S}$ might be linked to inorganic components that are dissolved by the acid treatment, which causes not only the ash content but also the $S$ content to decrease. The increase in the percentage of $\mathrm{H}$ might also be linked to the acid treatment and the presence of functional groups on the surface of the prepared $\mathrm{MgO}$ templated carbons. The oxygen content is similar to that of the carbon materials prepared from RF. In the case of the materials that contain BWM the $A C$ has a lower oxygen content. This is due to the previous heat treatment of the mixtures with BWM that facilitates the impregnation of the $\mathrm{Mg}$ citrate, favouring the introduction of elemental oxygen into the BWM molecules. Some of the oxygen remains on the surface of the carbon during carbonization providing it with a hydrophilic surface [14]. In contrast the carbons prepared by powder mixing have lower $\mathrm{C}, \mathrm{S}$ and $\mathrm{O}$ contents.

\subsection{Textural characteristics and morphology of the carbons}

The nitrogen sorption isotherms and pore size distributions corresponding to the ACs and nanocarbons are shown in Figures 2 and 3 respectively. The isotherms obtained are of type IV in the BDDT classification [15] which is typical of mesoporous solids that show an increase in the amount of nitrogen adsorbed in the mid $\mathrm{P} / \mathrm{P}_{0}$ range.

The isotherm corresponding to C3B shows greater nitrogen adsorption in the region of low relative pressure which indicates the presence of micropores related to 
the gasification reaction of carbon at high temperature. This reaction is caused by the $\mathrm{CO}_{2}$ derived from the decomposition of the $\mathrm{MgCO}_{3}$ into $\mathrm{MgO}$ and $\mathrm{CO}_{2}[16,17]$.

This isotherm also indicates there is a strong adsorption up to a relative pressure of 0.4 reflecting the presence of pores in the small mesopore region [4]. For relative pressures higher than 0.4 a marked hysteresis loop can be observed. In the isotherms corresponding to nanocarbons prepared by powder mixing it can be seen that there is an increase in the amount of nitrogen adsorbed at a lower relative $\left(P / P_{0}=\right.$ $0.41)$ pressure than those prepared by solution mixing $\left(P / P_{0}=0.48\right)$. This indicates that a smaller mesopore size results from PM preparation. In the case of the ACs the hysteresis loop is smaller and at a higher relative pressure the amount adsorbed is also lower. A mean mesopore size in the range of $4.5-5 . \mathrm{nm}$ in the case of powder mixing was obtained, while in the case of solution mixing the pores were around $7 \mathrm{~nm}$ excepting C3B Da Ny6 that had pores with a size of around $9 \mathrm{~nm}$ (Figure 3).

A study of the pore formation mechanism together with the XRD patterns of the carbon-coated materials before the $\mathrm{MgO}$ is eliminated may be useful for understanding the differences in the mesopore sizes obtained. When the $\mathrm{Mg}$ citrate mixture with the carbon precursor is heated, the carbon precursor melts at a specific temperature (117 ${ }^{\circ} \mathrm{C}$ for BWM and around $270{ }^{\circ} \mathrm{C}$ for the rest of the po lymers) causing the formation of a film on the surface of the $\mathrm{Mg}$ citrate particles. $\mathrm{MgO}$ is not formed until a temperature of $496{ }^{\circ} \mathrm{C}$ is reached. The layer of carbon precursor th at is covering the particles of $\mathrm{Mg}$ citrate decomposes but continues to cover the $\mathrm{Mg}$ citrate that eventually will decompose to give $\mathrm{MgO}$. The dissolution of the $\mathrm{MgO}$ will leave behind the carbon that now forms part of the pore walls whose size will depend on the crystallite size of the $\mathrm{MgO}$ formed [5]. The size of the $\mathrm{MgO}$ will depend on the precursor and the preparation procedure [6]. The higher crystallite size of MgO obtained when the SM procedure is used could be related to the slightly higher temperature of decomposition when $\mathrm{MgO}$ is formed as shown in Figure 1. The crystallite size can be calculated by applying the Scherrer equation to the (200) peak of the XRD pattern [11]. Figure 4 shows the XRD patterns corresponding to $\mathrm{C} 3 \mathrm{~B}$ and one example of each mixing procedure. The diffraction angles are the same for all the samples. The structure obtained is a facecentered cubic MgO Fm-3m (225). Nevertheless the line broadening at half the maximum intensity of the 200 peak is different in the three cases C3B > C3B RF_PM > C3B RF_SM. Consequently the crystallite size will be larger in the case of the solution mixing preparation technique. The crystallite sizes obtained were as follows: $5 \mathrm{~nm}$ for C3B-MgO, 6 nm for C3B RF_PM-MgO and C3B RF BWM 40_PM-MgO, 7 nm for C3B RF_SM-MgO and $9 \mathrm{~nm}$ for C3B PET Ny6_SM-MgO. The values obtained are in agreement with the pore sizes obtained in the BJH pore size distributions. These 
results confirm that the $\mathrm{MgO}$ nanoparticles which are located in the carbon matrix act as a template and that the mesopores of the C3B RF sample are formed once the $\mathrm{MgO}$ particles have been eliminated (see Fig S1). The production of nanocarbons of a specific pore size which is possible using the $\mathrm{MgO}$ template method is not possible in the preparation of the activated carbons, as can be seen in Figure $3[7,18]$.

The textural parameters of the ACs and MgO templated carbons are presented in Table 2. The results show that the $S_{B E T}$ values are significantly lower in the case of the ACs, especially when the RF/BWM blend is used as carbon precursor.

The nanocarbons and the AC prepared using RF as carbon precursor (samples: C3B RF_PM, C3B RF_SM and AC RF), show that solution mixing produces a material with a higher $\mathrm{S}_{\mathrm{BET}}, \mathrm{V}_{\mathrm{T}}, \mathrm{V}_{\text {microporos}}, \mathrm{V}_{\text {mesoporos }}$ and $\mathrm{V}_{\text {meso }} / \mathrm{V}_{\mathrm{T}}$ (Table 2). On the other hand, powder mixing (C3B RF_PM) yields a similar $S_{B E T}$ and $V_{\text {microporos }}$ to the $A C$. In the case of the carbons prepared from the 1:1 RF BWM blend, the difference between the $\mathrm{MgO}$ templated carbons and the $A C$ is remarkable. The results indicate that the inclusion of the BWM as carbon precursor with RF yields better results than those obtained for RF. The reason for this could be the improved fluidity resulting from the introduction of BWM, leading to a more effective coating of the $\mathrm{MgO}$ nanoparticles.

The carbons prepared by powder mixing and solution mixing in the case of the blends that contain BWM (C3B RF BWM 50 _PM and_SM) have similar $\mathrm{S}_{\mathrm{BET}}$ and micropore volumes although $\mathrm{V}_{\text {meso }}$ and $\mathrm{V}_{\mathrm{T}}$ are higher in the carbons prepared by solution mixing, as is the $\mathrm{V}_{\text {meso }} / \mathrm{V}_{\mathrm{T}}$ ratio. In general the $\mathrm{PM}$ procedure gives rise to carbons with $\mathrm{V}_{\text {meso }} / \mathrm{V}_{\mathrm{T}}$ ratio of around 0.7 while $\mathrm{SM}$ yields values of around 0.8 . All the nanocarbons produced from mixtures of $\mathrm{C} 3 \mathrm{~B}$ with the carbon precursors give lower $\mathrm{S}_{\mathrm{BET}}$ and higher $\mathrm{V}_{\text {meso }} / \mathrm{V}_{\mathrm{T}}$ values than when $\mathrm{C} 3 \mathrm{~B}$ is used alone. The mesopore ratio of the C3B carbon is more similar to that of the carbons produced with the PM procedure. The reason for this may be the fact that the decomposition of C3B observed in Figure 1 is also more similar to that of the carbon precursor prepared with the PM procedure than when the SM procedure is used.

Increasing the amount of C3B in the initial mixture as in the case of blends C3B RF BWM 40_PM (ratio C3B/BWM=1:1) and C3B RF BWM 50_PM (ratio $\mathrm{C} 3 \mathrm{~B} / \mathrm{BWM}=2: 1$ ) produces carbons with higher $\mathrm{S}_{\mathrm{BET}}, \mathrm{V}_{\text {meso }}$ and $\mathrm{V}_{\mathrm{T}}$ values due to higher availability of $\mathrm{MgO}$ nanoparticles [17-20].

A blend of pure thermoplastic polymers (Da Ny6) present in RF was also used with the two preparation procedures. The results shown in Table 2 indicate that PM produces a higher $\mathrm{S}_{\mathrm{BET}}$, although lower $\mathrm{V}_{\text {meso }}, \mathrm{V}_{\mathrm{T}}$ and $\mathrm{V}_{\text {meso }} / \mathrm{V}_{\mathrm{T}}$ values. A comparison of the textural characteristics of RF with those of the blend Da/Ny6 indicates that with the $\mathrm{PM}$ procedure carbons with improved textural characteristics are obtained (higher $\mathrm{S}_{\mathrm{BET}}$, 
$V_{T}$ and $V_{\text {meso }}$ ). In the case of solution mixing, the $S_{B E T}$ values are similar (around 650 $\mathrm{m}^{2} / \mathrm{g}$ ) although the $V_{\text {meso }}$ and $V_{T}$ values are higher in the polymer blend. The reason for the better textural characteristics in the blend of pure polymers is because in RF, the presence of components that do not melt on heating reduces the effectiveness of the procedure. In the literature $S_{B E T}$ values of 765 and $492 \mathrm{~m}^{2} / \mathrm{g}$ have been reported for $1: 1$ blends of pitch with $\mathrm{Mg}$ citrate and $\mathrm{MgO}$ respectively [5,14]. When polyethylene terephtalate was used as carbon precursor $S_{B E T}$ values of around $1000 \mathrm{~m}^{2} / \mathrm{g}$ were obtained with Mg citrate as MgO precursor [17]

In order to confirm the effectiveness of the proposed procedures with the carbon precursor used in the present research work, a blend of RF with $\mathrm{MgO}$ (1:1) was carbonized following the PM procedure. The carbon obtained once the $\mathrm{MgO}$ had been eliminated presented an $S_{B E T}$ area of $217 \mathrm{~m}^{2} / \mathrm{g}$ (the nitrogen isotherm has been included in Figure S2) which is a much higher value than the $43 \mathrm{~m}^{2} / \mathrm{g}$ value corresponding to the char obtained from RF [1].

BWM can be considered as a residual pitch and it is well known that to be able to produce porous carbons from bituminous coals or pitches three steps are essential i.e. oxidation, carbonization and activation. The results of this study prove that it is possible to produce nanocarbons from a bituminous waste and waste fibres without the need for activation.

In order to confirm the mechanism of formation of the porous texture, SEM images are presented in Figure 5 to show the morphology of the samples before and after the dissolution of $\mathrm{MgO}$. Figure $5 \mathrm{a}$ shows the presence of spherical clusters in the carbon matrix of sample C3B RF that was prepared by the powder mixing method, together with a close-up image of a cluster in the inset. After the elimination of the $\mathrm{MgO}$ (Figure 5a1) the carbon coating the $\mathrm{MgO}$ particles remains behind to form the pore walls with the same size as that of the dissolved $\mathrm{MgO}$. Figure $5 \mathrm{~b}$ shows an image of the carbon prepared from the RF BWM blend. It can be seen that the MgO appears more homogeneously distributed over the carbon surface. In fact the size of the clusters is around $500 \mathrm{~nm}$ in the first case (C3B RF-MgO) and 120-170 nm in the second (C3B RF BWM-MgO). This could be due to the greater fluidity of the precursor blend because of the BWM, that results in a better or more homogeneous impregnation of the $\mathrm{MgO}$ precursor by the carbon precursor. The dissolution of the $\mathrm{MgO}$ after carbonization produces pores that are evenly distributed over the carbon (Figure 5b1). SEM-EDX analysis of these clusters before and after the dissolution of $\mathrm{MgO}$ was carried out to see whether $\mathrm{MgO}$ was effectively eliminated from the nanocarbon leaving the voids that constitute the pores visible in Figure S1. 
The different morphologies obtained as a function of the precursor for the nanocarbons and ACs are shown in Figure 6. The nanocarbon C3B RF presents porous clusters of around $400-500 \mathrm{~nm}$ (Figure 6a). When the polymer blend is used as carbon precursor these clusters appear to be closer to one another and are of a smaller size, i.e., approx. $200 \mathrm{~nm}$ (Figure 6b). When BWM together with RF are used (Figure $6 \mathrm{c}$ ) in the initial blend the appearance is similar to that of the AC from RF (Figure 6d) the pores being homogeneously distributed around the carbon matrix.

\subsection{Surface chemistry}

Because of the importance of the surface chemistry for the performance of carbons, various techniques were used to characterize the materials prepared. The point of zero charge determines the surface charge of the sorbent at a given $\mathrm{pH}$ and this information reveals the possible electrostatic interactions between the sorbent and chemical species. Table 2 shows the $\mathrm{pH}_{\mathrm{PZC}}$ corresponding to the carbons prepared. As expected, the ACs present values of around 8-9 while the $\mathrm{MgO}$ template carbons, due to acid treatment, present lower values, in the range of 3-5. The evolution of $\mathrm{CO}$ and $\mathrm{CO}_{2}$ during the TPD experiments is shown in Figure 7. The curves corresponding to the $\mathrm{ACs}$ are completely different to those corresponding to the $\mathrm{MgO}$ templated carbons. The $\mathrm{CO}_{2}$ profile of the latter indicates the presence of strong carboxylic acids reflected in the peak in the temperature range between $237-297^{\circ} \mathrm{C}$. The peak between 377-447 ${ }^{\circ} \mathrm{C}$ in the $\mathrm{CO}_{2}$ profile indicates the presence of weaker acids [21]. The curves corresponding to the $\mathrm{CO}$ evolution of the $\mathrm{MgO}$ templated carbons show a peak with a maximum at $400{ }^{\circ} \mathrm{C}$ indicative of aldehydes or $\alpha$-ketones [22], the presence of phenols and carbonyl groups being reflected in the peaks at $660-725{ }^{\circ} \mathrm{C}$ and $700-900{ }^{\circ} \mathrm{C}$ respectively [21-25]. The profiles of the evolution of $\mathrm{CO}$ and $\mathrm{CO}_{2}$ with temperature obtained for the ACs are completely different. Peaks in the $\mathrm{CO}_{2}$ curve in the range where carboxylic acids decompose can be appreciated although not as clearly as in the $\mathrm{MgO}$ templated carbons. The peaks present in the range between $550-600^{\circ} \mathrm{C}$ and 631 $822{ }^{\circ} \mathrm{C}$ correspond to the decomposition of peroxides and lactones respectively [2123,26]. The peak at around $650{ }^{\circ} \mathrm{C}$ in the $\mathrm{CO}_{2}$ plot of the ACs can be assigned to the decomposition of mineral matter $[27,28]$. The CO peak at high temperature (800-900 $\left.{ }^{\circ}\right)$ indicates the decomposition of basic groups such as quinones in the activated carbons $[21,22,24]$.

The amounts of $\mathrm{CO}$ and $\mathrm{CO}_{2}$ desorbed during the TPD analysis are summarized in Table 3. The values recorded indicate that the carbon surface is not highly functionalized. The amount of $\mathrm{CO}$ desorbed is greater than that of $\mathrm{CO}_{2}$ for all the samples. The amount of $\mathrm{CO}+\mathrm{CO}_{2}$ desorbed in the ACs is greater than in the $\mathrm{MgO}$ 
templated carbons. Of course, it is necessary to bear in mind that some of the $\mathrm{CO}_{2}$ evolved from the ACs is due to the removal of inorganic matter which is not present in the acid treated samples [28]. The $\mathrm{CO} / \mathrm{CO}_{2}$ ratio is higher in the case of the blends prepared with solution mixing. In order to confirm the results obtained by TPD the ACs and nanocarbons were studied by Infrared spectroscopy (see supplementary material).

\subsection{Adsorption of a reactive dye}

The results of adsorption of CBY with time are presented in Figure 8 expressed as the amount of CBY adsorbed ( $q, \mathrm{mg} / \mathrm{g}$ ) as a function of time (min). An increase in the adsorption time implies an increase in the amount of CBY removed before equilibrium is reached. Although the time needed to reach equilibrium was the same for both samples $2880 \mathrm{~min}$ (48h) the percentages of CBY removed from the solution were different. At equilibrium, C3B RF BWM 50 _SM removed 83\% of CBY dye as against $73 \%$ in the case of C3B RF BWM 50 _PM. Although the $A_{B E T}$ of both samples was very similar, the mesopore volume and size were different. The difference in the percentage of dye removed is assigned to the higher $\mathrm{V}_{\text {meso }} / \mathrm{V}_{\mathrm{T}}$ ratio and mesopore size of the samples prepared with the solution-mixing procedure.

\section{Conclusions}

Mesoporous carbons were prepared from various carbon precursors. It was found that their textural characteristics and surface chemistry were strongly dependent on the method used for their preparation. The ACs show a lower surface area, pore volume and ratio of mesopores than the $\mathrm{MgO}$ templated carbons. In addition the latter present pores with a controllable size depending on the preparation procedure. The $\mathrm{MgO}$ templated carbons prepared from the blend RF/BWM have an area three times greater than that of the corresponding AC.

It has been demonstrated that it is possible to produce nanocarbons with a narrow pore size distribution and a high surface area from thermoplastic precursors. The size of the mesopores obtained depends on the size of the $\mathrm{MgO}$ crystallite formed from the $\mathrm{MgO}$ precursor. Solution mixing yields slightly larger pores and larger mesopore volume than powder mixing. Their surface chemistries are also different. While the ACs have basic surface functional groups, the $\mathrm{MgO}$ templated carbons have a larger amount of acidic groups such as carboxylic acids. The solution mixing procedure appears to be more effective for removing large molecules such as CBY than powder mixing.

\section{Acknowledgements}


The research leading to these results has received funding from the Spanish MICINN Project reference CTM2009-10227. BA thanks the Government of the Principado de Asturias for the award of a predoctoral grant with funds from PCTI-Asturias. 


\section{References}

[1] B. Acevedo, C. Barriocanal, R. Álvarez, Fuel 113 (2013) 817- 825.

[2] L.K. Edward, C.K. Ko, G. McKay, Carbon 42 (2004) 2789-2805.

[3] T. Morishita, Y. Soneda, T. Tsumura, M. Inagaki, Carbon 44 (2006) 2360-2367.

[4] Y. Soneda, M. Kodama, Boletín del Grupo Español Carbón 28 (2013) 15-17.

[5] T. Morishita, T. Tsumura, M. Toyoda, J. Przepiórski, A.W. Morawski, H. Konno, M. Inagaki, Carbon 48 (2010) 2690 - 2707.

[6] Y.S. Wang, C.Y. Wang, M.M. Chen, New Carbon Materials 24 (2) (2010) 187190.

[7] M.Inagaki, H. Orikasa, T. Morishita, RSC Advances 1 (2011) 1620-1640.

[8] B. Acevedo, C. Barriocanal, Fuel 125 (2014) 155-163.

[9] A.M. Fernández, C. Barriocanal, R. Alvarez, J. Hazard. Mater. 203-204 (2012) 236-43.

[10] F. Parres, J.E. Crespo-Amorós, A. Nadal-Gisbert, J. Appl. Polymer. Sc. 113 (2009) 2136-2142.

[11] M. Faraldos, C. Goberna, Técnicas de análisis y caracterización de materiales, 2nd Ed, CSIC - Consejo Superior de Investigaciones Científicas, España, 2011.

[12] C. Moreno-Castilla, M.V. Lopez-Ramon, F. Carrasco-Marin, Carbon 38 (2000) $1995-2001$.

[13] S.A.A. Manssour, Termal decomposition of magnesium citrate 14-hydrate, Themochimical Acta 233 (1994) 231-242.

[14] D.P. Xu, S.-H. Yoon, I. Mochida, W.M.Qiao, Y.G. Wang, L.C.Ling, Micro. Meso. Mater. 115 (2008) 461-468.

[15] S. Brunauer, L.S. Deming, W.S. Deming, E. Teller, J. Amer. Chem. Soc. 62 (1940) 1723-1728.

[16] M. Sevilla, A.B. Fuertes, J. Mater. Chem. A. (2013) 13738-13741

[17] J. Przepiórski, J Karolczyk, K. Takeda, T. Tsumura, M. Toyoda, A.W. Morawski, End. Eng. Chem. Res 48 (2009)7110-7116.

[18] T. Morishita, K.Ishihara, M. Kato, M. Inagaki, Carbon 45 (2007) 203-228.

[19] M. Inagaki, M. Kato, T. Morishita, K. Morita, K. Mizuuchi, Carbon 45 (2007) 1105-1136.

[20] Y.S. Wang, C.Y. Wang, New Carbon Materials 25(5) (2010) 376-381.

[21] H.F. Gorgulho, J.P. Mesquita, F. GonÇalves, M.F.R. Pereira, J.L.Figueiredo, Carbon 46 (2008) 1544-1555.

[22] J.L. Figueiredo, M.F.R. Pereira, M.M.A. Freitas, J.J.M. Órfao, Ind. Eng. Chem. Res. 46 (2007) 4110-4115. 
[23] U. Zielke, K.J. Hüttinger, W.P. Hoffman, Carbon 34 (8) (1996) 983-998.

[24] B. Marchon, J. Carrazza, H. Heinemann, G.A. Somorjai. Carbon 26 (1988) 507514.

[25] J.L. Figueiredo, M.F.R. Pereira, M.M.A. Freitas, J.J.M. Órfao, Carbon 37 (1999) 1379-1389.

[26] Q-L. Zhuang, T. Kyotani, A. Tomita, Energy Fuels 8 (1994) 714-718.

[27] C. O. Ania. In Green Carbon materials advances and applications. Thomas E. Rufford, John Zhu, Denisa Hulicova-Jurcakova Eds. Pan Stanford Publishing 2009.

[28] J.M. Rosas, J. Bedia, J. Rodríguez-Mirasol, T. Cordero, Fuel Proc. Technol. 91 (2010) 1345-1354 
Table 1. Elemental analysis of carbons.

\begin{tabular}{lccccc}
\hline \multicolumn{1}{c}{ Samples } & C & $\mathrm{N}$ & $\mathrm{S}$ & $\mathrm{H}$ & $\mathrm{O}$ \\
& $(\mathrm{wt} \%$, daf $)$ & (wt.\%, daf) & (wt.\%, daf) & (wt.\%, daf) & (wt.\%, daf) \\
\hline C3B & 95.5 & 0.9 & 0.0 & 0.8 & 3.6 \\
C3B Da Ny6_PM & 91.9 & 2.0 & 0.0 & 1.5 & 4.5 \\
C3B Da Ny6_SM & 94.7 & 1.7 & 0.0 & 1.4 & 4.8 \\
C3B RF_PM & 93.0 & 1.0 & 0.6 & 1.2 & 3.7 \\
C3B RF_SM & 94.0 & 0.9 & 0.8 & 1.1 & 4.5 \\
C3B RF BWM 50_PM & 92.8 & 1.5 & 0.6 & 1.0 & 3.9 \\
C3B RF BWM 50_SM & 93.4 & 1.1 & 0.7 & 1.1 & 4.1 \\
C3B RF BWM 40_PM & 94.7 & 1.4 & 0.6 & 0.9 & 4.1 \\
AC RF & 97.9 & 0.6 & 4.7 & 0.2 & 2.5 \\
AC RF BWM & 96.0 & 1.8 & 3.1 & 0.4 & 1.4 \\
\hline
\end{tabular}

daf: dry ash free 
Table 2. Textural properties and $\mathrm{pH}_{\mathrm{PzC}}$ values.

\begin{tabular}{lcccccc}
\hline \multicolumn{1}{c}{ Sample } & $\begin{array}{c}\mathrm{S}_{\mathrm{BET}} \\
\mathrm{m}^{2} / \mathrm{g}\end{array}$ & $\begin{array}{c}\mathrm{V}_{\mathrm{T}} \\
\mathrm{cm}^{3} / \mathrm{g}\end{array}$ & $\begin{array}{c}\mathrm{V}_{\mathrm{DR}, \mathrm{N} 2} \\
\mathrm{~cm}^{3} / \mathrm{g}\end{array}$ & $\begin{array}{c}\mathrm{V}_{\text {meso }} \\
\mathrm{cm}^{3} / \mathrm{g}\end{array}$ & $\mathrm{V}_{\text {meso }} / \mathrm{V}_{\mathrm{T}}$ & $\mathrm{pH}_{\mathrm{PZC}}$ \\
\hline C3B & 1738 & 1.59 & 0.57 & 1.01 & 0.64 & 4.5 \\
$\begin{array}{l}\text { C3B Da } \\
\text { Ny6_PM }\end{array}$ & 819 & 1.10 & 0.27 & 0.82 & 0.75 & 3.9 \\
$\begin{array}{l}\text { C3B Da } \\
\text { Ny6_SM }\end{array}$ & 646 & 1.71 & 0.23 & 1.48 & 0.87 & 3.6 \\
C3B RF_PM & 447 & 0.62 & 0.15 & 0.47 & 0.75 & 3.6 \\
C3B RF_SM & 654 & 1.28 & 0.24 & 1.05 & 0.82 & 4.1 \\
$\begin{array}{l}\text { C3B RF BWM } \\
\text { 50_PM }\end{array}$ & 762 & 0.85 & 0.27 & 0.58 & 0.68 & 3.6 \\
$\begin{array}{l}\text { C3B RF BWM } \\
\text { 50_SM }\end{array}$ & 752 & 1.35 & 0.27 & 1.08 & 0.80 & 3.3 \\
$\begin{array}{l}\text { C3B RF BWM } \\
\text { 40_PM }\end{array}$ & 502 & 0.62 & 0.18 & 0.43 & 0.71 & 4.1 \\
$\begin{array}{l}\text { AC RF } \\
\text { AC RF BWM }\end{array}$ & 219 & 0.16 & 0.08 & 0.08 & 0.49 & 8.3 \\
\hline
\end{tabular}


Table 3. Amounts of $\mathrm{CO}$ and $\mathrm{CO}_{2}$ released during the TPD experiments and calculated by integrating the areas under the corresponding peaks.

\begin{tabular}{lcccc}
\hline & $\mathrm{CO}$ & $\mathrm{CO}_{2}$ & $\mathrm{O}$ & $\mathrm{CO} / \mathrm{CO}_{2}$ \\
& $(\mu \mathrm{mol} / \mathrm{g})$ & $(\mu \mathrm{mol} / \mathrm{g})$ & $(\mu \mathrm{mol} / \mathrm{g})$ & \\
\hline C3B & 967.1 & 296.5 & 1560.0 & 3.26 \\
C3B Da Ny6_PM & 416.6 & 179.1 & 774.8 & 2.33 \\
C3B Da Ny6_SM & 639.7 & 255.0 & 1149.8 & 2.51 \\
C3B RF_PM & 403.0 & 217.3 & 837.6 & 1.85 \\
C3B RF_SM & 388.1 & 203.6 & 795.2 & 1.91 \\
C3B RF BWM 50_PM & 394.9 & 160.3 & 715.5 & 2.46 \\
C3B RF BWM 50_SM & 557.7 & 218.9 & 995.5 & 2.55 \\
C3B RF BWM 40_PM & 451.4 & 243.8 & 939.0 & 1.85 \\
AC RF & 915.4 & 603.1 & 2121.6 & 1.52 \\
AC RF BWM & 904.3 & 444.2 & 1792.7 & 2.04 \\
\hline
\end{tabular}



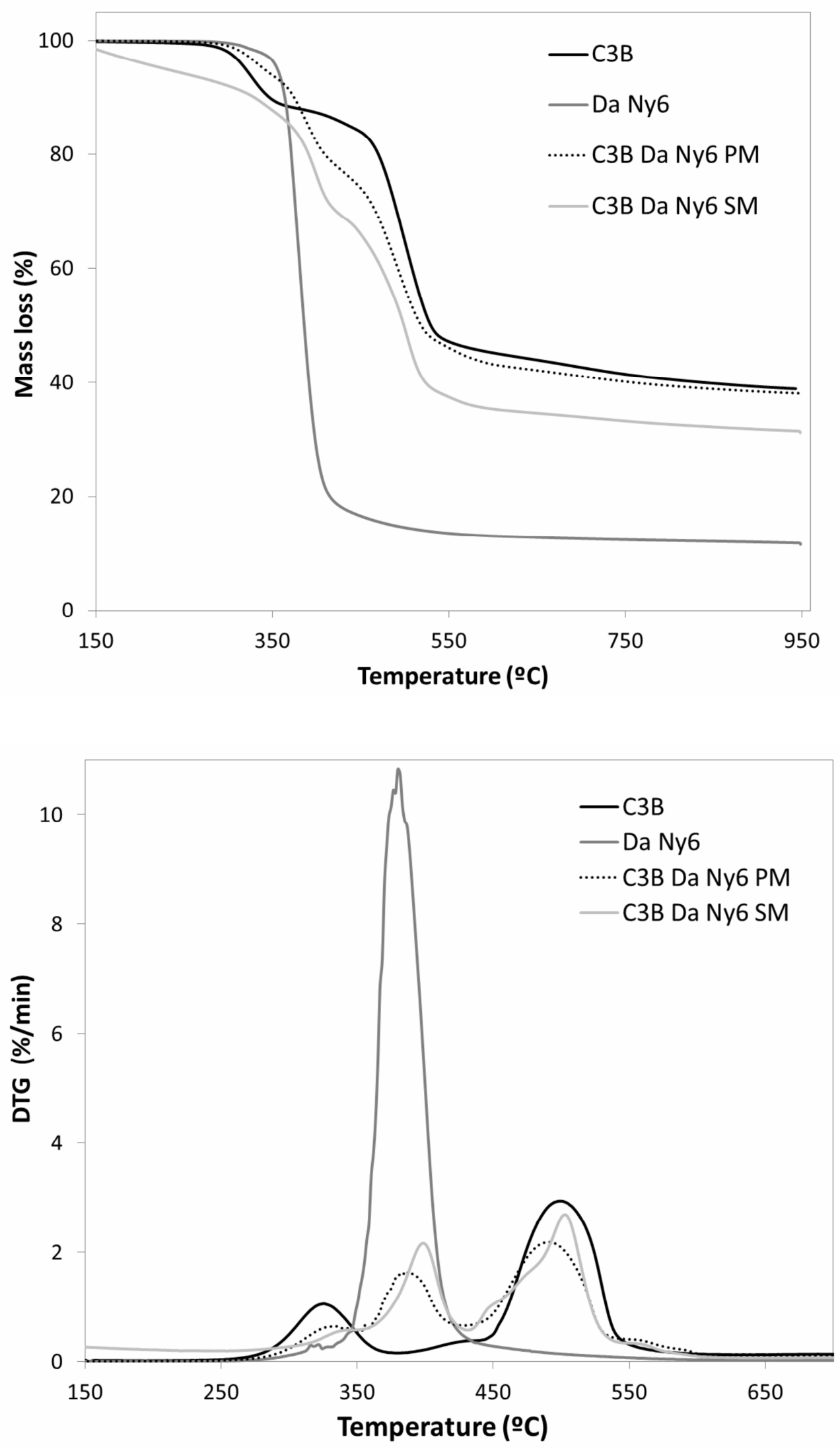

Figure 1. TG/DTG curves of Mg citrate, the polymer blend (DA Ny6) and the mixtures of $\mathrm{Mg}$ citrate with the polymer blend prepare by powder and solution mixing. 


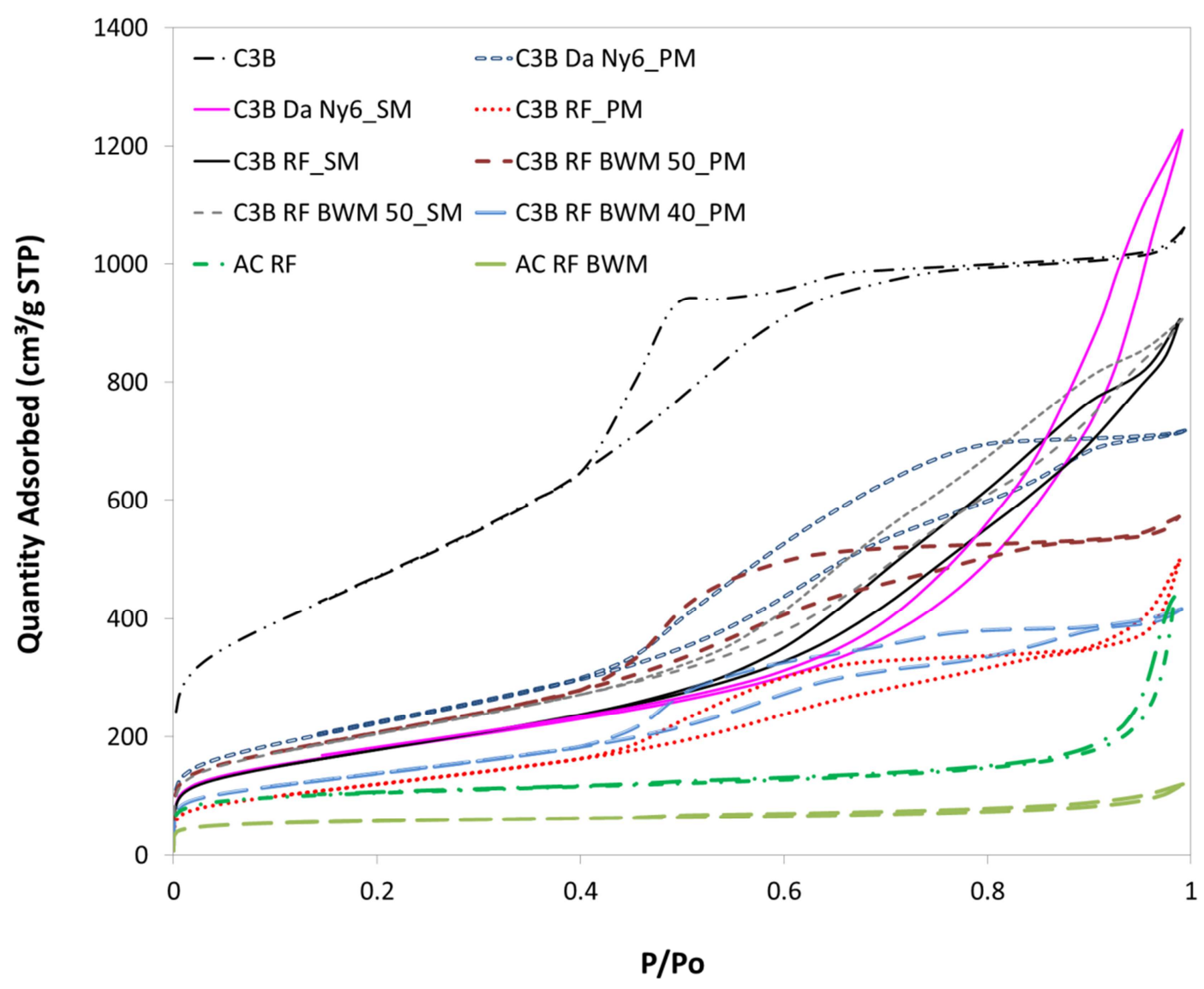

Figure 2. Nitrogen sorption isotherms corresponding to the $\mathrm{MgO}$ templated carbons and ACs. 

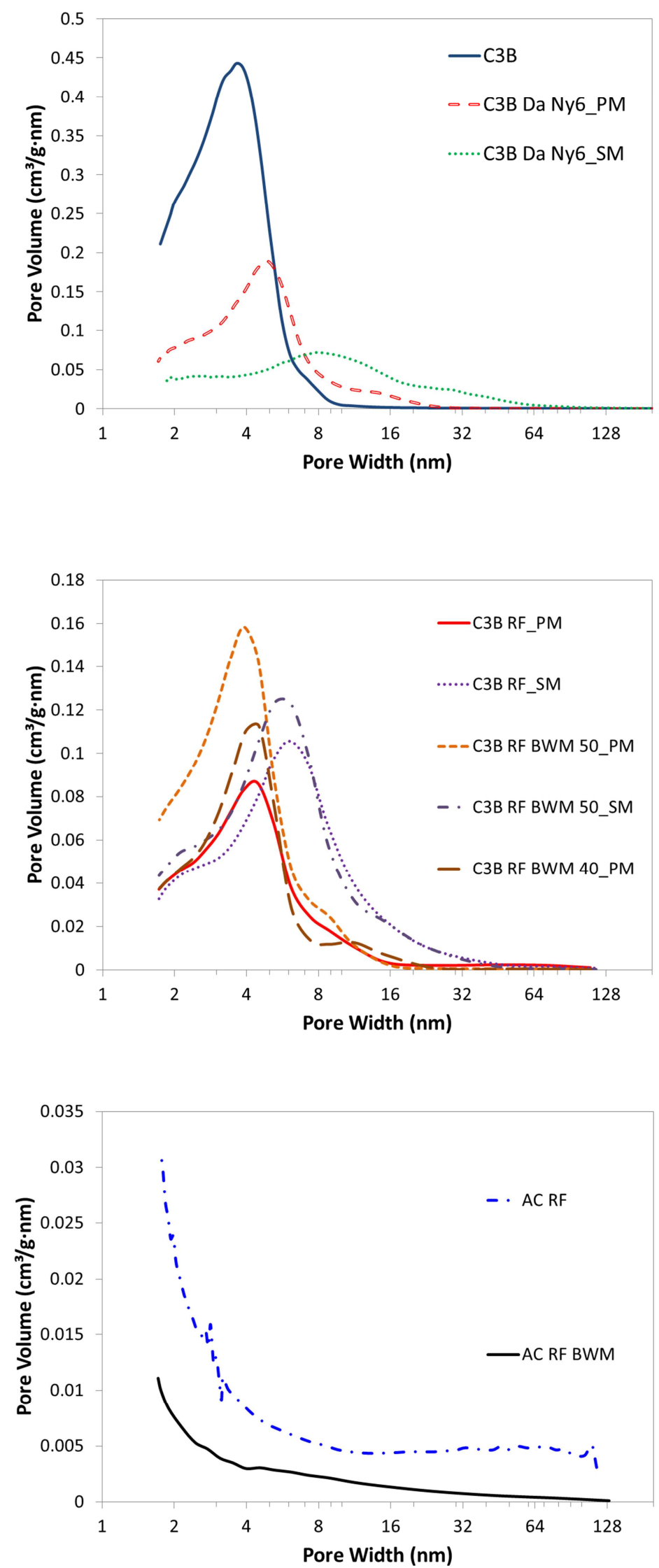

Figure 3. Pore size distribution of the MgO carbons and ACs. 


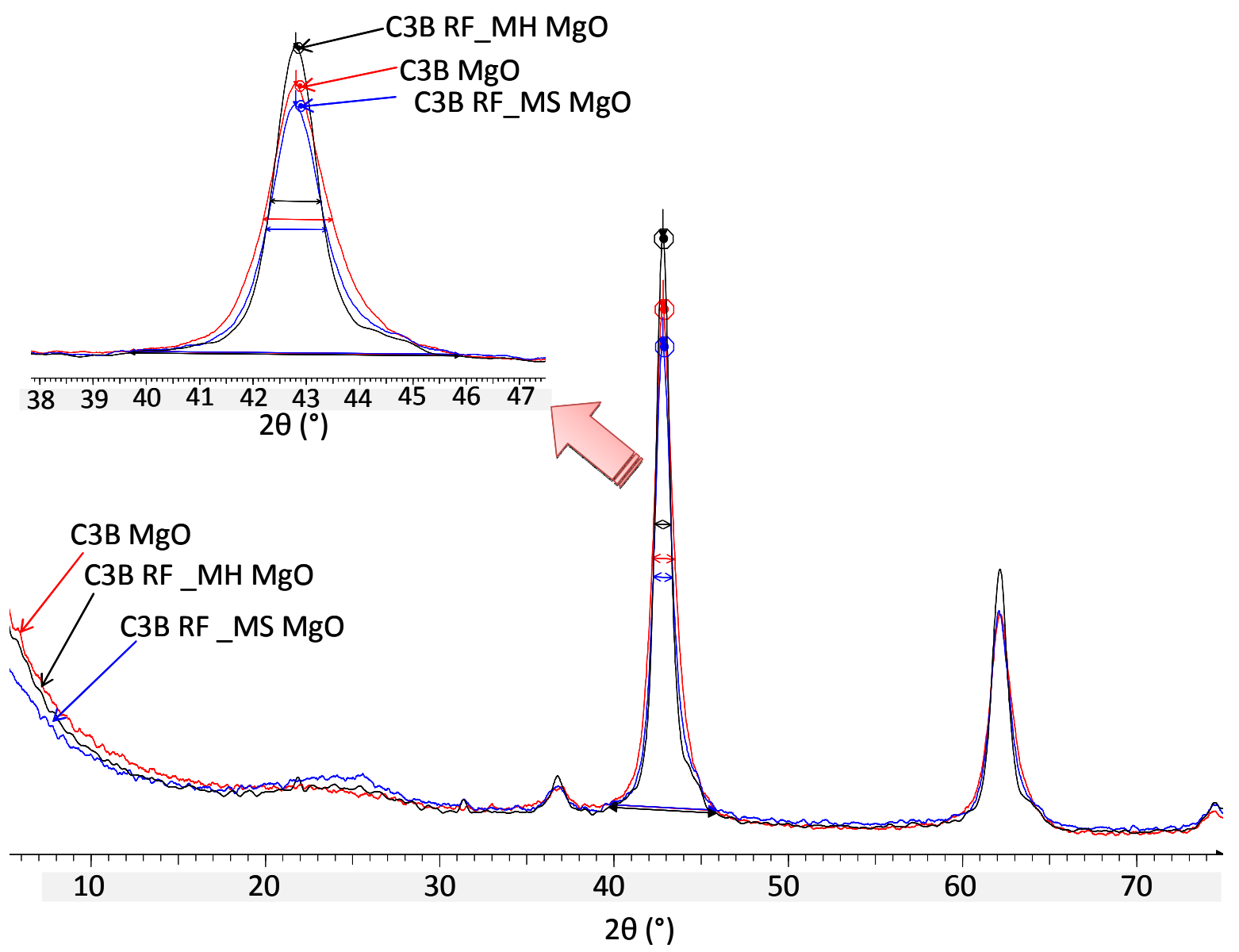

Figure 4. DRX diffraction patterns before $\mathrm{HCl}$ washing. 

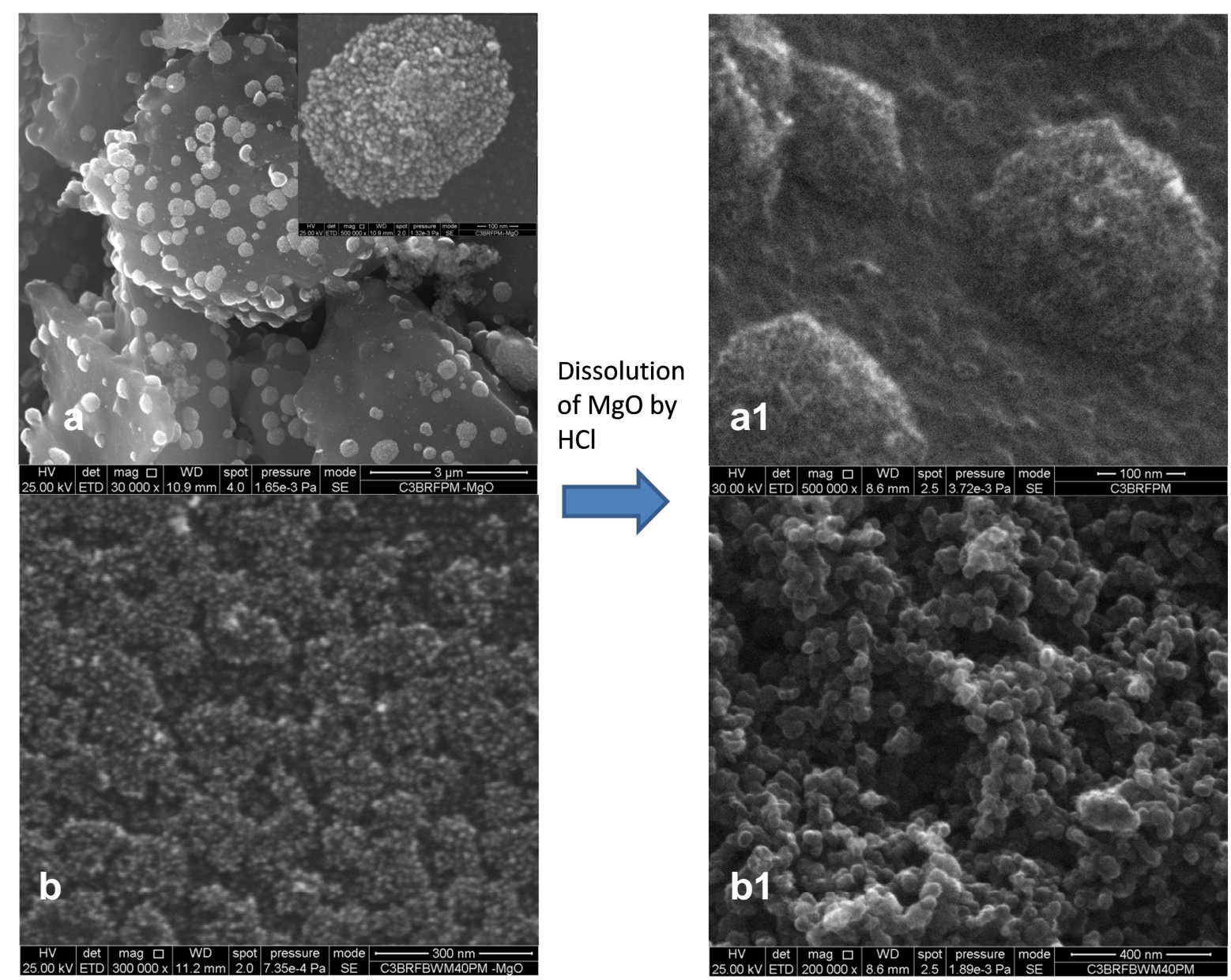

Figure 5. SEM images of carbons before and after $\mathrm{MgO}$ dissolution. a) C3B RF_PM$\mathrm{MgO}$, a1) C3B RF_PM, b) C3B RF BWM 40_PM-MgO and b1) C3B RF BWM 40_PM. 


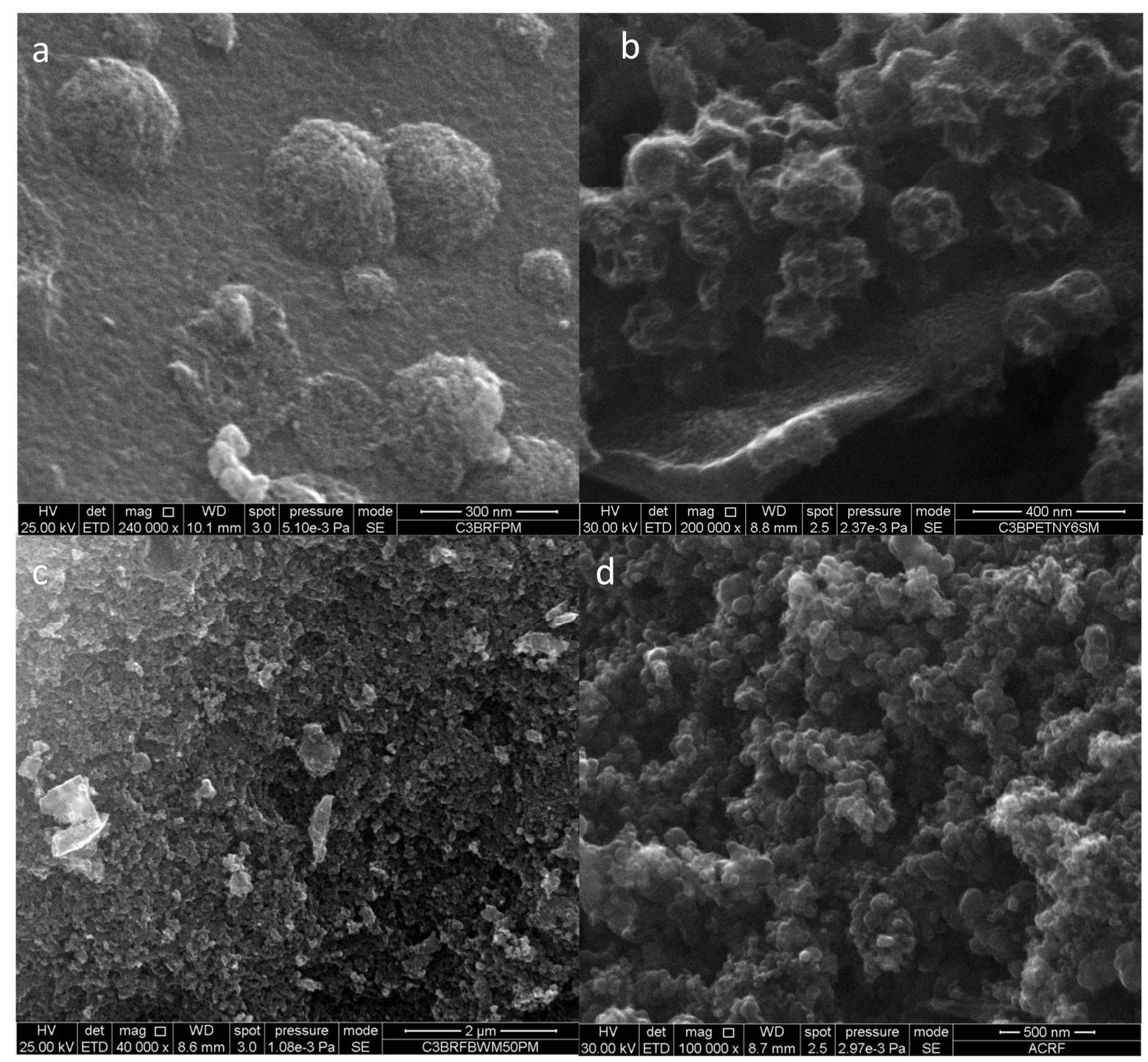

Figure 6. SEM. MgO-template carbons derived from different precursors. a) C3B RF_PM, b) C3B Da Ny6_SM, c) C3B RF BWM50_PM, d) AC RF. 

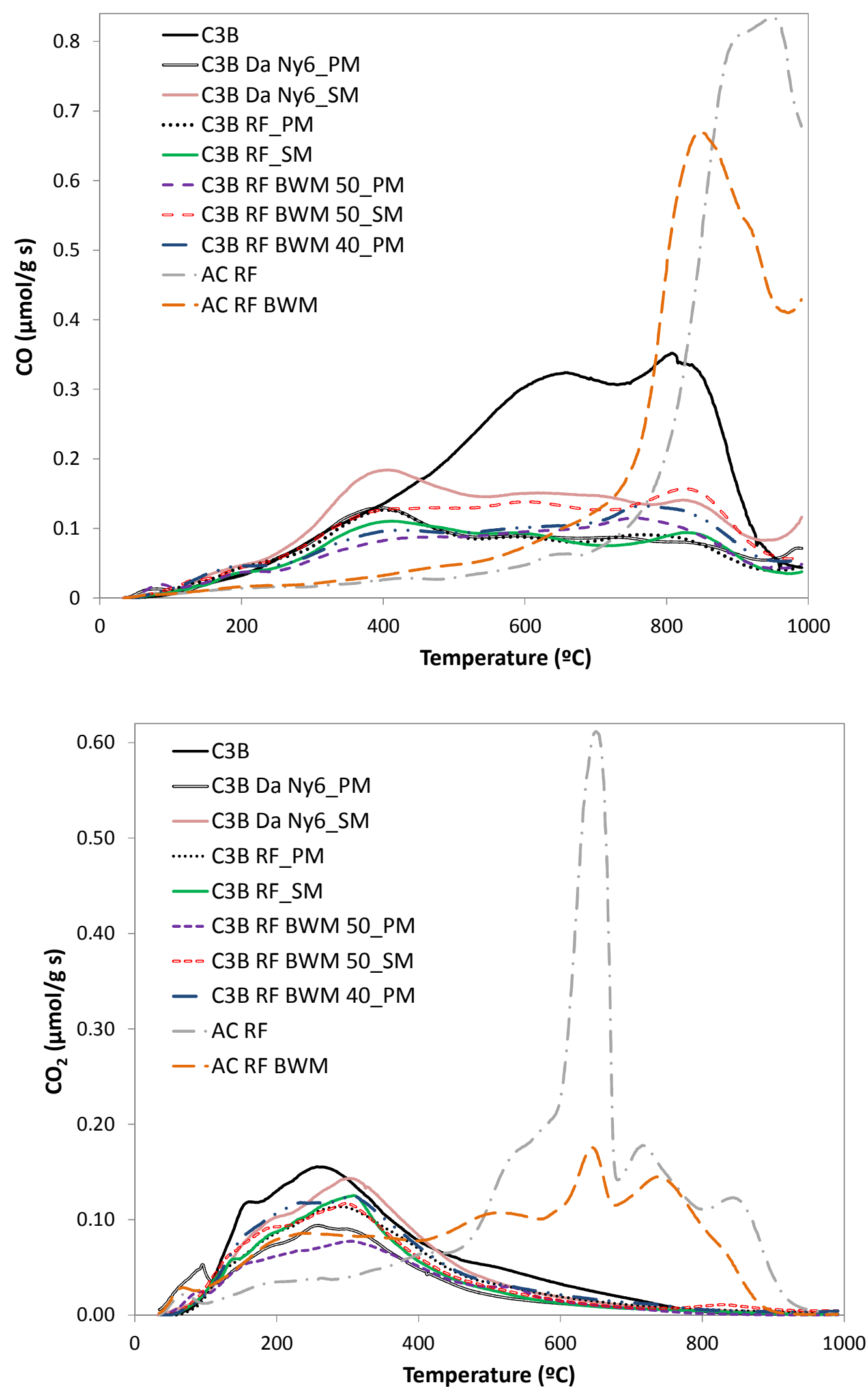

Figure 7. $\mathrm{CO}$ and $\mathrm{CO}_{2}$ TPD spectra corresponding to the nanocarbons and $\mathrm{ACs}$ 


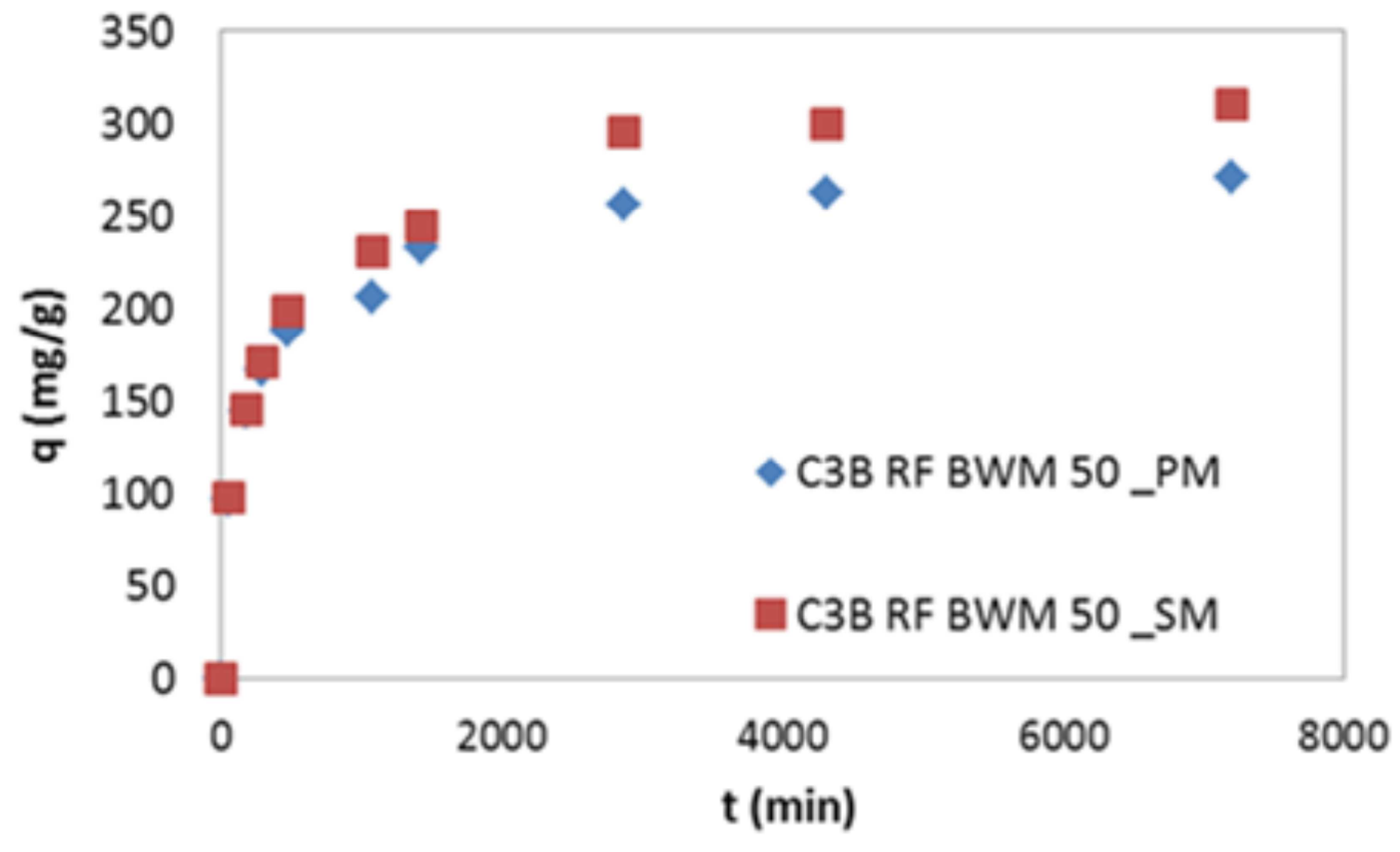

Figure 8. Adsorption curve of CBY on nanocarbons. 


\title{
Supplementary Material
}

\section{Preparation of MgO-templated carbons from waste polymeric fibres}

\author{
Beatriz Acevedo, Carmen Barriocanal \\ Instituto Nacional del Carbón, INCAR-CSIC, Apartado 73, 33080 Oviedo, \\ Spain
}

Table S1. Proximate and elemental analysis of the raw materials used.

\begin{tabular}{lcc}
\hline & RF & BW \\
\hline VM $^{\mathrm{a}}($ wt.\% db \\
Ash(wt.\% db) & $72.9^{\mathrm{d}}$ & $68.2^{\mathrm{d}}$ \\
$\mathrm{C}$ (wt.\% db) & $4.6^{\mathrm{d}}$ & $0.2^{\mathrm{d}}$ \\
$\mathrm{H}$ (wt.\% db) & 68.2 & 86.7 \\
$\mathrm{~N}(\mathrm{wt} . \% \mathrm{db})$ & 6.7 & 5.1 \\
$\mathrm{~S}$ (wt.\% db) & 1.1 & 4.4 \\
$\mathrm{O}($ wt.\% db) & 1.03 & 2.39 \\
$\mathrm{C} / \mathrm{H}^{\mathrm{c}}$ & 18.6 & 2.3 \\
\hline
\end{tabular}

a: volatile matter, b: dry basis, c: atomic ratio, $\mathrm{d}$ : from thermogravimetric analysis.

\section{Experimental}

Scanning Electron Microscopy-X-ray Energy Dispersive Spectroscopy (SEM-EDX) The samples was examined using ascanning electron microscope (SEM), Quanta 3D FEG (FEI Company), coupled to an X-ray Energy Dispersive Spectrometer (EDX) for local elemental analysis.

Infrared spectra using the diffuse reflectance mode (DRIFT) spectra were recorded on a Nicolet Magna-IR560 spectrometer equipped with a mercury cadmium telluride detector (MCT-A) which operates at a sub-ambient temperature. The particle size of the samples was $<63 \mu \mathrm{m}$ and the spectra were recorded from 4000 to $650 \mathrm{~cm}^{-1}$ by 128 interferograms at a resolution of $4 \mathrm{~cm}^{-1}$.

\section{Results and Discussion}

Figure S1 shows the nitrogen sorption isotherms corresponding to carbon prepared from a blend 1:1 of $\mathrm{RF}$ and $\mathrm{MgO}$ after dissolution of $\mathrm{MgO}$ and a char prepared from RF. 
Infrared spectroscopy is a useful technique for confirming the presence of the oxygenated functional groups detected by TPD. Figure S3 shows the diffuse reflectance infra-red spectra (DRIFTS) of the carbons prepared. In order to make a correct interpretation of the spectra it is necessary to bear in mind that each functional group gives rise to bands at different wavenumbers. A broad band in the 3600-3200 $\mathrm{cm}^{-1}$ range is observed due to the $\mathrm{O}-\mathrm{H}$ stretching of hydroxyl groups, carboxylic groups and adsorbed water. The presence of this band together with another in the range of $1665-1760 \mathrm{~cm}^{-1}$ and $1120-1200 \mathrm{~cm}^{-1}$ is indicative of the existence of carboxylic acids [S1]. These bands are visible in all the carbons. Some interference in the last range could be due to the presence of mineral matter in the ACs. The presence of adsorption bands characteristic of $-\mathrm{CH}_{3}$ and $-\mathrm{CH}_{2}$ at 2950, 2920 and $2860 \mathrm{~cm}^{-1}$ especially in the spectra of the ACs indicates the presence of aliphatic species in the carbons [S2,S3]. In the spectra of the $\mathrm{MgO}$ templated carbons, bands at $1300-1230 \mathrm{~cm}^{-1}$ are assigned to non-saturated ketones together with the absorption bands in the $1650-1750 \mathrm{~cm}^{-1}$ range corresponding to $\mathrm{C}=\mathrm{O}$ [S1]. The presence of phenols in the nanocarbons as shown by TPD is confirmed by the bands in the range of $1000-1220 \mathrm{~cm}^{-1}$ for $\mathrm{C}-\mathrm{OH}$ and between $1160-1200 \mathrm{~cm}^{-1}$ and $2500-3620 \mathrm{~cm}^{-1}$ for $\mathrm{O}-\mathrm{H}$. The presence of lactone and quinone groups shown by the TPD analysis of the ACs is confirmed by the presence of absorption bands in the ranges of $1160-1370 \mathrm{~cm}^{-1}$ and $1675-1790 \mathrm{~cm}^{-1}$ (lactones) and $1550-1680 \mathrm{~cm}^{-1}$ (quinones) due to $\mathrm{C}=\mathrm{O}$ moieties [S1,S2,S3]. The complicated nature of the absorption bands in the ranges of $1750-1700 \mathrm{~cm}^{-1}, 1650-1610$ and $1570-1520 \mathrm{~cm}^{-1}$ suggests that bands associated to aromatic rings and double-bond vibrations are overlapping the absorption bands because $\mathrm{C}=\mathrm{O}$ [S3].

\section{References}

[S1] J.L. Figueiredo, M.F.R. Pereira, M.M.A. Freitas, J.J.M. Órfao, Carbon 37 (1999) 1379-1389.

[S2] B. Smith, Infrared spectral interpretation: a systematic approach, CRC Press, Boca Raton, 1998.

[S3] S. Biniak, G. Szymanski, J. Siedlewski, A. Swiatkowski, Carbon 35 (1997)17991810. 

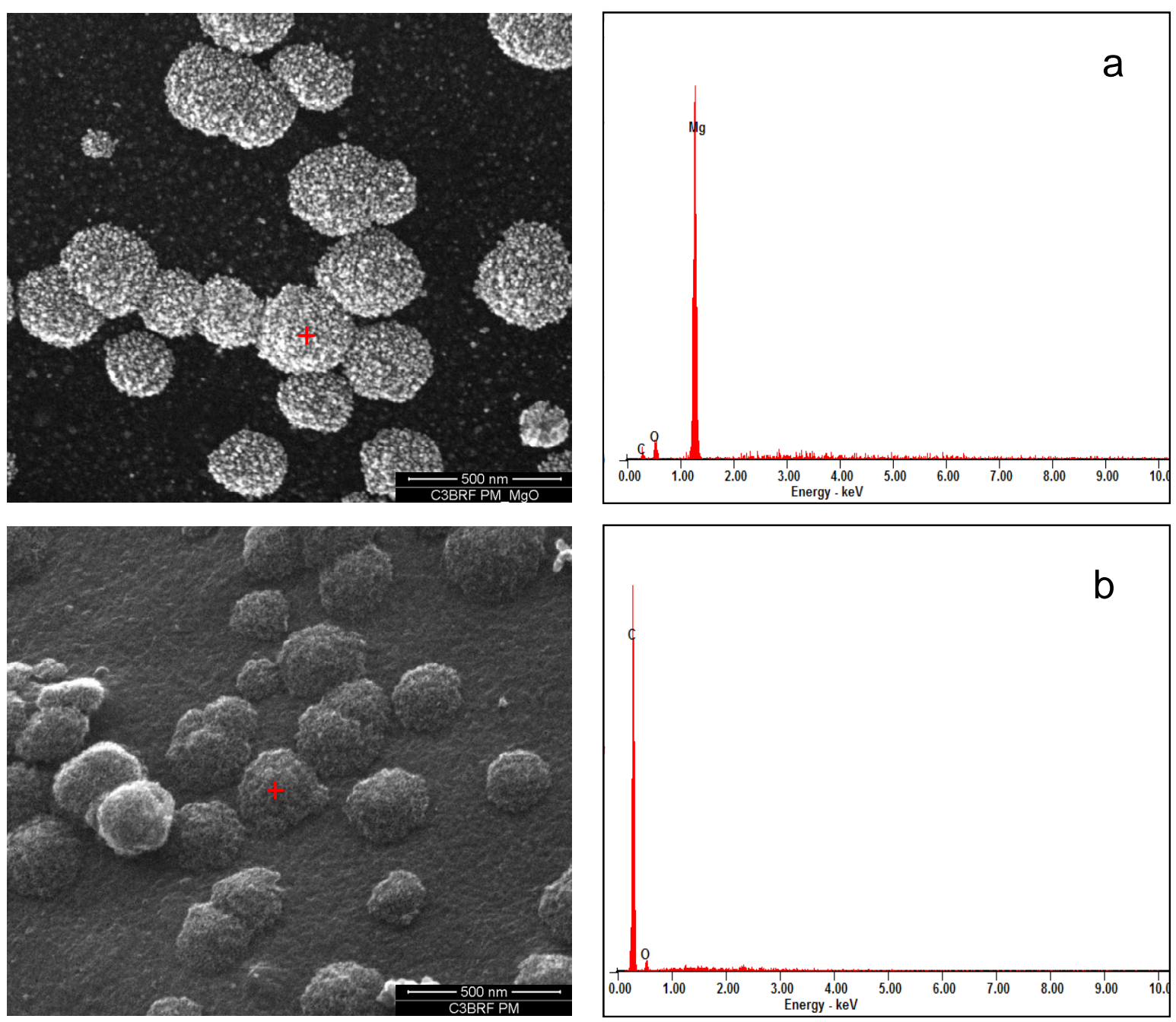

Figure S1. SEM-EDX image showing the composition in the spot. A) before acid washing and $b$ ) after acid washing. 


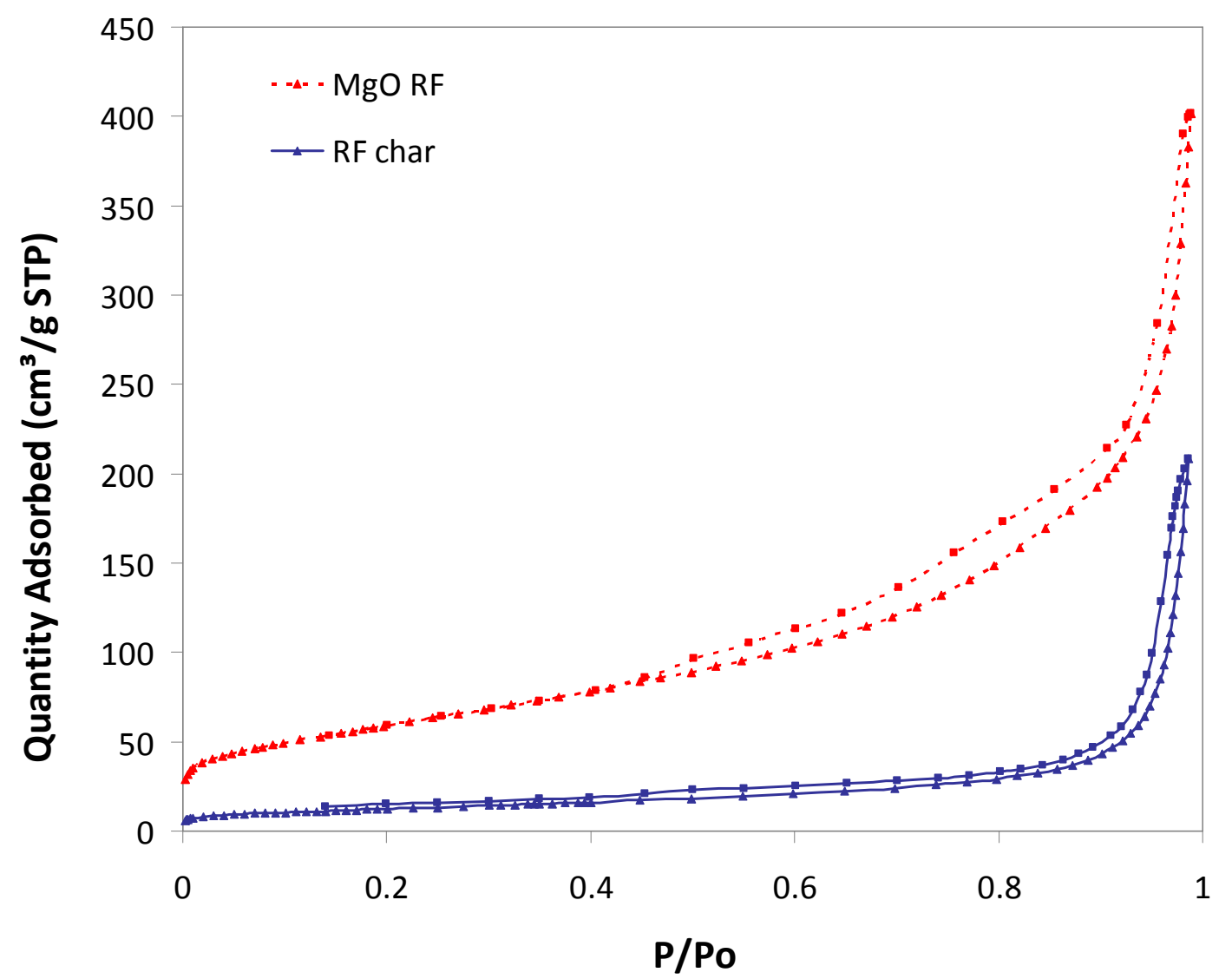

Figure S2. Nitrogen sorption isotherms corresponding to carbon prepared from a blend $1: 1$ of $\mathrm{RF}$ and $\mathrm{MgO}$ after dissolution of $\mathrm{MgO}$ and a char prepared from RF as in ref [1]. 

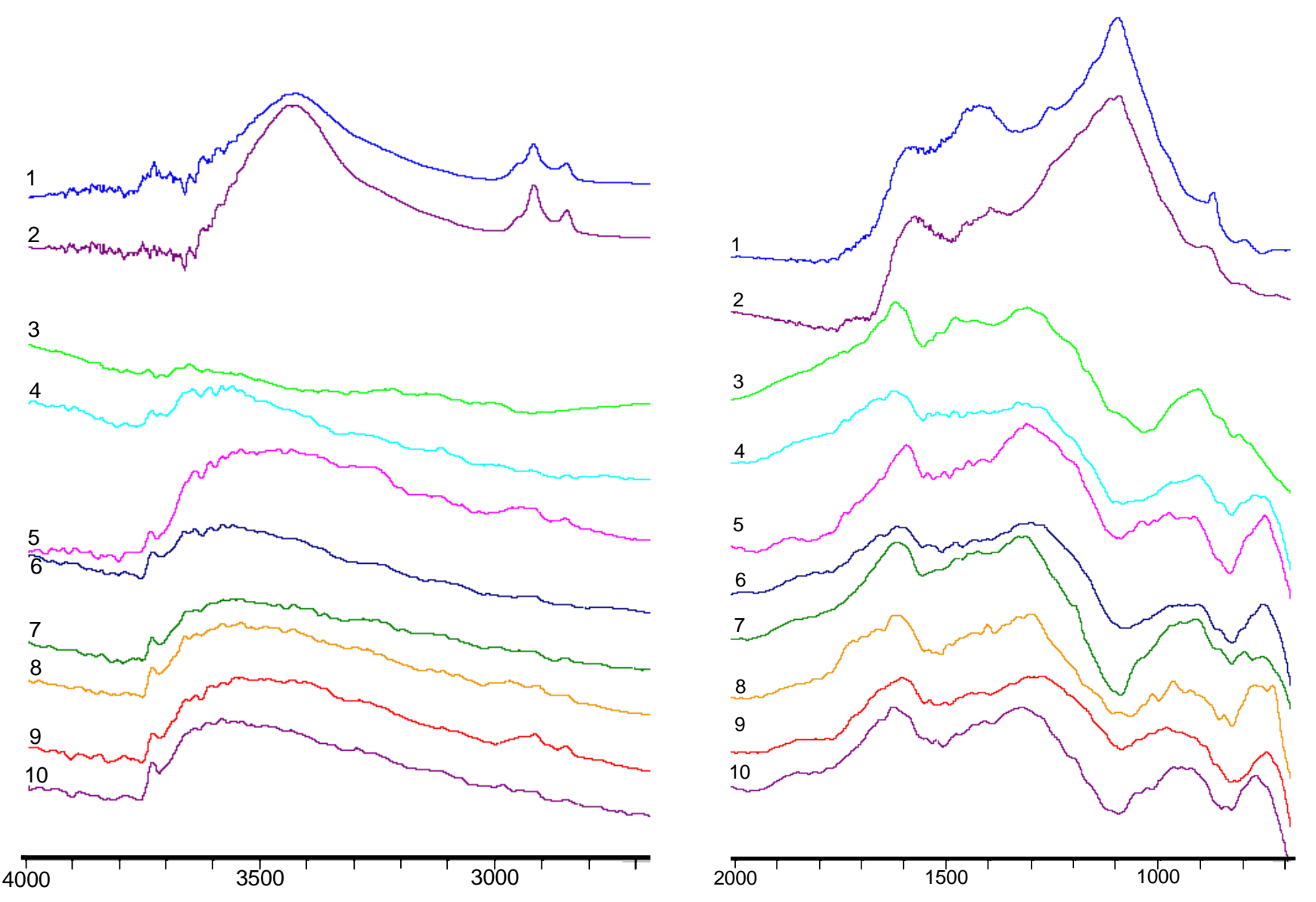

Figure S3. FTIR-DRIFT. 1. AC RF, 2. RF BWM, 3. C3B, 4. C3B Da Ny6_PM, 5. C3B Da Ny6_SM, 6. C3B RF_PM, 7. C3B RF_SM, 8. C3B RF BWM 50_PM, 9. C3B RF BWM 50_SM, 10. C3B RF BWM 40_PM 